\section{Estimating Leaf Chlorophyll Content of Buffaloberry Using Normalized Difference Vegetation Index Sensors}

\author{
Ji-Jhong Chen ${ }^{1}$, Shuyang Zhen ${ }^{2}$, and Youping Sun $^{1}$
}

ADDITIONAL INDEX wORDs. chlorophyll meter, NDVI, Shepherdia, SPAD, transmitted light

Summary. Commercial optical chlorophyll meters estimate relative chlorophyll content using the ratio of transmitted red light and near-infrared (NIR) light emitted from a red light-emitting diode (LED) and an NIR LED. Normalized difference vegetation index (NDVI) sensors have red and NIR light detectors and may be used to estimate chlorophyll content by detecting the transmitted red and NIR light through leaves. In this study, leaf chlorophyll content of 'Torrey' buffaloberry (Shepherdia $\times$ utahensis) plants treated with $0 \mathrm{~mm}$ [zero nitrogen (N)], $2 \mathrm{~mm}$ (medium N), or $4 \mathrm{~mm}$ (ample N) ammonium nitrate for 3 weeks were evaluated using two commercial chlorophyll meters and NDVI sensors. The absolute chlorophyll content was determined using chlorophyll extraction. Our results showed that plants receiving ample $\mathrm{N}$ and medium $\mathrm{N}$ had decreased transmitted red light (i.e., greater absorption in red light). Measurements of optical chlorophyll meters, NDVI sensors, and chlorophyll extraction similarly showed that plants receiving medium $\mathbf{N}$ and ample $\mathbf{N}$ had greater leaf chlorophyll content than those receiving zero $\mathbf{N}$. Relative leaf chlorophyll content estimated using NDVI sensors correlated positively with those from the chlorophyll meters $\left(P<0.0001 ; r^{2}\right.$ range, $\left.0.56-0.82\right)$. Therefore, our results indicate that NDVI measurements are sensitive to leaf chlorophyll content. These NDVI sensors, or specialized sensors developed using similar principles, can be used to estimate the relative chlorophyll content of nursery crops and help growers adjust fertilization to improve plant growth and nutrient status.

L eaf chlorophyll content is an important index for plant $\mathrm{N}$ status, photosynthesis capacity, and stress tolerance (Taiz et al., 2015). It is common to estimate leaf chlorophyll content using nondestructive optical chlorophyll meters (Ferrarezi et al., 2020; Neilsen et al., 1995). Relative chlorophyll content is estimated using the ratio of transmitted red light and NIR light emitted by a red and an NIR LED, respectively, through a leaf (Monje and Bugbee, 1992). Transmitted red light through a leaf is related inversely to the chlorophyll content because chlorophylls absorb red light efficiently (Taiz et al., 2015). Conversely, chlorophylls absorb little NIR light, thus NIR light can be used as a reference for a nonchlorophyll absorption spectrum (Monje and Bugbee, 1992). The SPAD-502 chlorophyll meter developed by Konica Minolta (Tokyo, Japan) is commercially available to estimate relative chlorophyll content. Recently, multiple chlorophyll meters such as the CL-01 chlorophyll content meter (Hansatech Instruments, Hitchin,
UK), the Dualex leafclip sensor (ForceA, Paris, France), and the MC-100 chlorophyll meter (Apogee Instruments, Logan, UT) have been developed following a similar protocol (Kalaji et al., 2017).

Optical chlorophyll meters are simple, quick, and nondestructive tools for determining chlorophyll content (Parry et al., 2014), but efforts have been made to develop alternative options because of their high prices (Richardson et al., 2002; Vesali et al., 2015; Yang et al., 2003). NDVI sensors equipped with red and NIR light detectors are mostly used in remote sensing to estimate vegetation coverage (Wang et al., 2012). NDVI sensors are sensitive to the red and NIR light of solar radiation and may be used to estimate leaf chlorophyll content through determining transmitted red and NIR light to help growers adjust fertilization.

In our study, an NDVI sensor (S2-412-SS, Apogee Instruments) and two commercial chlorophyll meters (MC-100 and SPAD-502) were used to measure leaf chlorophyll content of 'Torrey' buffaloberry (Shepherdia $\times$ utahensis). Chlorophyll extraction was also conducted to assess the accuracy of estimating leaf chlorophyll content using NDVI sensors. Because sunlight varies greatly depending on weather and seasonality, one concern about using NDVI sensors to estimate chlorophyll content is if changes in solar radiation affect the chlorophyll content measurements. The impacts of sunlight and electric light source (e.g., halogen) on NDVI measurements were compared.

\section{Materials and methods}

Plant materials and treatMENTS. On 22 Mar. 2019, terminal cuttings of buffaloberry were collected from the Utah State University (USU) Greenville Research Farm (North Logan, UT). The cuttings were propagated following the protocol of Chen et al. (2020). On 10 June, buffaloberry rooted cuttings were transplanted into l-gal injectionmolded polypropylene containers (PC1D-4; Nursery Supplies, Orange, CA) filled with a soilless substrate (Metro-Mix 820; Sun Gro Horticulture, Agawam, MA). Plants were irrigated with tap water $(\mathrm{pH}, 7.89)$ before the experiment. All plants were grown in the USU Research Greenhouse (Logan, UT) at a temperature of $25 / 20^{\circ} \mathrm{C}$ day/night. Light intensities were

\begin{tabular}{llll}
\hline $\begin{array}{l}\text { Units } \\
\text { To convert U.S. to SI, } \\
\text { multiply by }\end{array}$ & U.S unit & SI unit & $\begin{array}{l}\text { To convert SI to U.S., } \\
\text { multiply by }\end{array}$ \\
\hline 29.5735 & $\mathrm{fl} \mathrm{oz}$ & $\mathrm{mL}$ & 0.0338 \\
0.3048 & $\mathrm{ft}$ & $\mathrm{m}$ & 3.2808 \\
3.7854 & gal & $\mathrm{L}$ & 0.2642 \\
2.54 & inch(es) & $\mathrm{cm}$ & 0.3937 \\
25.4 & inch $(\mathrm{es})$ & $\mathrm{mm}$ & 0.0394 \\
645.1600 & $\mathrm{inch}{ }^{2}$ & $\mathrm{~mm}$ & 0.0016 \\
305.1517 & $\mathrm{oz} / \mathrm{ft}^{2}$ & $\mathrm{~g} \cdot \mathrm{m}^{-2}$ & 0.0033 \\
10.7639 & $\mathrm{~W} / \mathrm{ft}^{2}$ & $\mathrm{~W} \cdot \mathrm{m}^{-2}$ & 0.0929 \\
$\left({ }^{\circ} \mathrm{F}-32\right) \div 1.8$ & ${ }^{\circ} \mathrm{F}$ & ${ }^{\circ} \mathrm{C}$ & $\left({ }^{\circ} \mathrm{C} \times 1.8\right)+32$
\end{tabular}


recorded hourly using a heated silicon chip pyranometer (SP-230, Apogee Instruments) mounted to a weather station at the Greenville Research Farm, about $1000 \mathrm{~m}$ away from the greenhouse. A light transmission rate of $68 \%$ was used when calculating the daily light integral (DLI) inside the greenhouse, and the DLI was $16.8 \pm$ $2.5 \mathrm{~mol} \cdot \mathrm{m}^{-2} \cdot \mathrm{d}^{-1}$ (mean $\pm \mathrm{SD}$ ) during the experiment. Supplemental light was provided using 1000 -W high-pressure sodium lamps (Hydrofarm, Petaluma, CA) from 0600 to $2200 \mathrm{HR}$. Lamps were turned on at an average intensity of $130 \pm 18 \mu \mathrm{mol} \cdot \mathrm{m}^{-2} \cdot \mathrm{s}^{-1}$ (mean \pm SD) at the plant canopy level when the greenhouse light intensity was less than $544 \mu \mathrm{mol} \cdot \mathrm{m}^{-2} \cdot \mathrm{s}^{-1}$.

On 24 Oct., 15 uniform plants were sorted into three groups. Relative leaf chlorophyll content was similar among the three groups, as confirmed using a SPAD-502 chlorophyll meter. From 24 Oct. to 20 Nov., I L N-free Utah Monocot/ Dicot solution (Bugbee, 2004) with $0 \mathrm{~mm}$ (zero $\mathrm{N}), 2 \mathrm{~mm}$ (medium $\mathrm{N}$ ), or $4 \mathrm{~mm}$ (ample $\mathrm{N}$ ) added ammonium nitrate $\left(\mathrm{NH}_{4} \mathrm{NO}_{3}\right)$ at $\mathrm{pH} 7.5$ was applied manually every other

\footnotetext{
Received for publication 18 Jan. 2021. Accepted for publication 18 Mar. 2021.

Published online 11 May 2021.

${ }^{1}$ Department of Plants, Soils, and Climate, Utah State University, 4820 Old Main Hill, Logan, UT 84322

${ }^{2}$ Department of Horticultural Sciences, Texas A\&M University, 2133 TAMU, College Station, TX 77843
}

This research was supported in part by the U.S. Department of Agriculture (USDA) National Institute of Food and Agriculture Hatch project UTA01381, New Faculty Start-Up Funds from the Office of Research and Graduate Studies, the Center for WaterEfficient Landscaping, and the Utah Agricultural Experiment Station (UAES) at Utah State University.

This article is approved as UAES journal paper no. 9444.

We are grateful for technical assistance from Mitch Westmoreland, Paul Kusuma, and Will Wheeler.

The content of this article is solely the responsibility of the authors and does not necessarily represent the official views of the funding agencies. Mention of a trademark, proprietary product, or vendor does not constitute a guarantee or warranty of the product by the USDA or the American Society for Horticultural Science and does not imply its approval to the exclusion of other products or vendors that also may be suitable.

J.-J.C. and Y.S. are the corresponding authors. E-mail: njijhong.chen@gmail.com or nyouping.sun@ usu.edu.

This is an open access article distributed under the CC BY-NC-ND license (https://creativecommons. org/licenses/by-nc-nd/4.0/).

https://doi.org/10.21273/HORTTECH04808-21 day to each plant in its corresponding treatment.

UNIFORMITY OF LEAF CHLOROPHYLL. Before the $\mathrm{N}$ treatment, leaf chlorophyll content of buffaloberry was measured using an MC-100 chlorophyll meter. Fifteen mature leaves were sampled randomly from 15 buffaloberry plants. Ten measurements were recorded on each leaf, and the mean value was calculated. The $\mathrm{CV}$ (SD $\div$ mean) was computed according to Parry et al. (2014) to study the uniformity of chlorophyll within a single leaf.

Transmission OF RED AND NIR LIGHT. On 16 Nov., incident red and NIR light from solar radiation, and transmitted red and NIR light from leaves of buffaloberry were recorded using NDVI sensors in an open field near the USU Research Greenhouse (lat. $41^{\circ} 45^{\prime} 28^{\prime \prime} \mathrm{N}$, long. $111^{\circ} 48^{\prime} 47^{\prime \prime} \mathrm{W}$ ) from 1321 to 1536 HR. All plants were moved from the greenhouse to the field, and five leaves were sampled from three randomly chosen plants in each treatment. Afterward, all plants were moved to a darkroom at the USU Research Greenhouse, and measurements were taken in the darkroom with two 500-W halogen lights (PQS45; Regent Lighting, Basel, Switzerland). The distance from the halogen lights to the NDVI sensor was 84 $\mathrm{cm}$. A downward-looking NDVI sensor was placed on the abaxial surface of a leaf to record the transmitted red and NIR light levels. The incident red and NIR light levels were recorded using a sensor of hemispherical $180^{\circ}$ view (S2-411-SS, Apogee Instruments). Transmission (percentage) of red and NIR light was

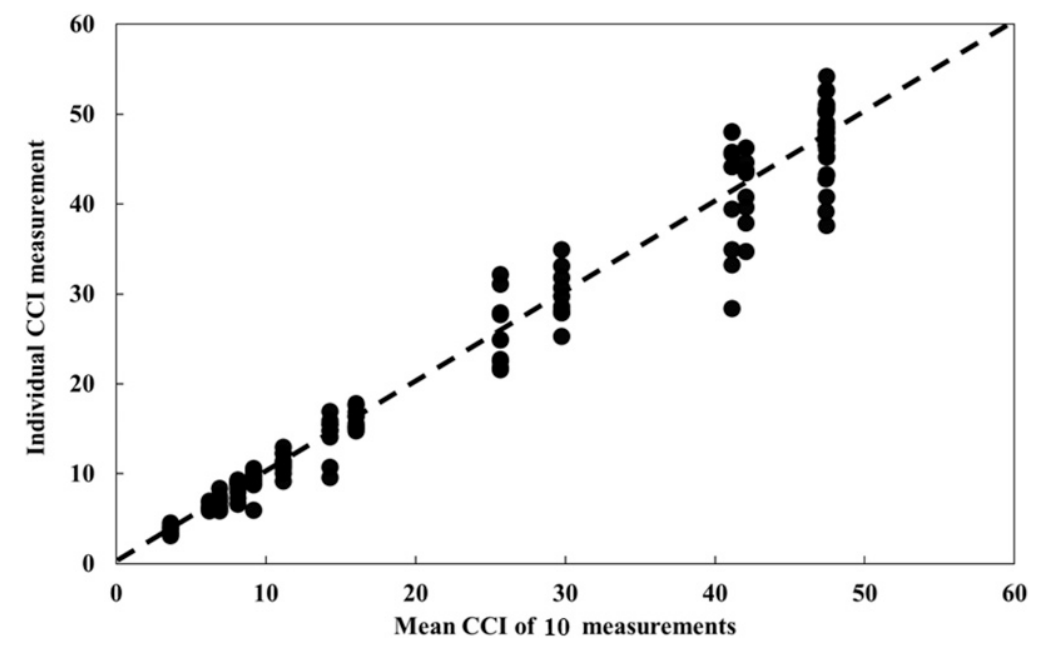

Fig. 1. Uniformity of chlorophyll. Ten chlorophyll content index (CCI) measurements were made on each of 15 leaves sampled from 15 buffaloberry plants. The mean $\mathrm{CV}$ ( $\mathrm{SD} /$ mean) was $11 \%$ for chlorophyll content measurements. calculated using the fraction between transmitted light and incident irradiation. The relative chlorophyll content $\left(\mathrm{Chl}_{\text {NDVI }}\right)$ was estimated using the transmitted red and NIR light from the halogen lights or solar radiation using the following equation:

$$
\mathrm{Chl}_{\mathrm{NDVI}}=\ln
$$

$\times\left(\frac{\text { Percent transmission of NIR light }}{\text { Percent transmission of red light }}\right)$.

The NDVI sensors (output measured in watts per square meter) were measured using a datalogger (CRI000X; Campbell Scientific, Logan, UT). Measurements of soil plant analysis development (SPAD) and chlorophyll content index (CCI) were made with the SPAD502 chlorophyll meter and MC-100 chlorophyll meter, respectively, on the same leaves used for $\mathrm{Ch}_{\mathrm{NDVI}}$ measurements under solar radiation and halogen lights.

Chlorophyll extraction. Chlorophyll extraction was conducted on 20 Nov. following the protocol for determining absolute chlorophyll concentration (Parry et al., 2014). Three leaves of each plant were sampled from the top one-third or the bottom one-third of the main shoot. A disk from each leaf was sampled using a \#5 cork borer with an area of $78.5 \mathrm{~mm}^{2}$. Three leaf disks sampled from the same shoot position and the same plant were placed in a vial with $5 \mathrm{~mL} 99.7 \%$ dimethyl sulfoxide (DMSO) (Fisher Scientific, Hampton, $\mathrm{NH}$ ) and incubated in water at $65^{\circ} \mathrm{C}$ for $2 \mathrm{~h}$. 
All leaf disks became transparent after all chlorophylls were extracted in the solution. A $3-\mathrm{mL}$ aliquot was transferred to an optical-grade analysis cell for measuring light absorbance at 649.1 and $665.1 \mathrm{~nm}$ (Wellburn, 1994) using a spectrophotometer (ultraviolet-2401PC; Shimadzu Corp., Kyoto, Japan) with a resolution of $0.1 \mathrm{~nm}$. Chlorophyll $\mathrm{a}$ and $\mathrm{b}$ concentrations were calculated using the equation for DMSO and for $0.1-$ to $0.5-\mathrm{nm}$ spectral resolution (Wellburn, 1994). In addition, the chlorophyll $a$ and $b$ concentrations for the top and bottom of the main shoot were averaged.

An analysis of variance was performed to test the effects of $\mathrm{NH}_{4} \mathrm{NO}_{3}$ on leaf chlorophyll content. Mean separation among treatments was adjusted using the Tukey-Kramer method for multiplicity at $\alpha=0.05$. Regression analyses were conducted for relative chlorophyll contents measured using optical meters and NDVI sensors. All statistical analyses were performed using the PROC Mixed procedure in SAS Studio 3.8 (SAS Institute, Cary, NC).

\section{Results}

VARIATION OF CHLOROPHYLL DISTRIBUTION. Chlorophyll distributed uniformly within a single leaf of buffaloberry with a typical leaf length of $39.3 \mathrm{~mm}$ and width of $24.5 \mathrm{~mm}$ (Fig. 1). The $\mathrm{CV}$ for chlorophyll distribution among 15 buffaloberry leaves ranged from $4 \%$ to $16 \%$, with a mean value of $11 \%$.

CHLOROPHYLL CONTENT DETERMINED BY OPTICAL METERS AND CHLOrophyll eXtraction. Plants showed different visual quality at the termination of the experiment (Fig. 2), with very few yellow leaves on plants receiving medium $\mathrm{N}$ and ample $\mathrm{N}$, but

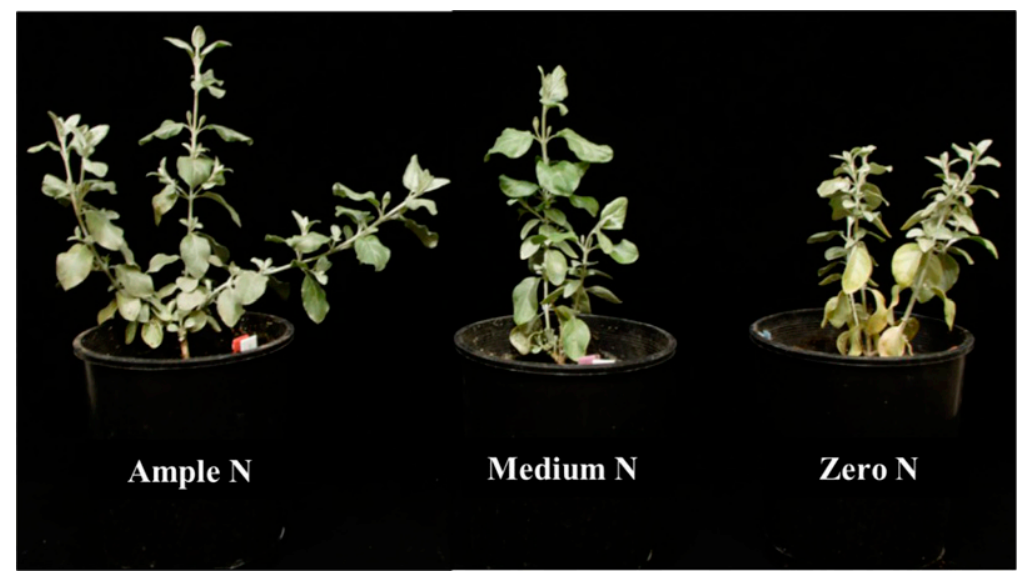

Fig. 2. Buffaloberry plants treated with nitrogen (N)-free Utah Monocot/Dicot solution (Bugbee, 2004) with $0 \mathrm{~mm}($ zero $\mathrm{N}), 2 \mathrm{~mm}($ medium $\mathrm{N})$, or $4 \mathrm{~mm}$ (ample $\mathrm{N}$ ) added ammonium nitrate for 3 weeks (photo was taken 20 Nov. 2019).

more than $50 \%$ of leaves on plants treated with zero $\mathrm{N}$ were yellow. Leaf chlorophyll content estimated using the SPAD-502 meter was greater for plants treated with ample $\mathrm{N}$ and medium $\mathrm{N}$ compared with plants treated with zero N (Table 1). Similar results were recorded using an MC-100 chlorophyll meter (Table 1).

For plants receiving ample $\mathrm{N}$ or medium $\mathrm{N}$, both chlorophyll $\mathrm{a}$ and $\mathrm{b}$ concentrations of leaves at the top of the main shoot were similar to those at the bottom of the main shoot (Table 2). However, when plants were irrigated with zero $\mathrm{N}$, chlorophyll $\mathrm{a}$ and $\mathrm{b}$ concentrations were greater in leaves at the top of main shoot than those at the bottom. When averaged for leaves at the top and bottom of the main shoot, chlorophyll $\mathrm{a}$ and $\mathrm{b}$ concentrations were, respectively, 0.26 and $0.1 \mathrm{~g} \cdot \mathrm{m}^{-2}$ for plants treated with ample $\mathrm{N}, 0.25$ and 0.1 $\mathrm{g} \cdot \mathrm{m}^{-2}$ for plants receiving medium $\mathrm{N}$, and 0.13 and $0.06 \mathrm{~g} \cdot \mathrm{m}^{-2}$ for plants receiving zero $\mathrm{N}$.

Transmission RED AND NIR LIGHT. The red and NIR light intensities under halogen lights were $0.22 \pm$ 0.01 and $0.19 \pm 0.01 \mathrm{~W} \cdot \mathrm{m}^{-2}$ (mean \pm SD), respectively (Fig. 3). The red light intensity transmitted through leaves of plants treated with zero $\mathrm{N}$ was greater than that from plants treated with ample $\mathrm{N}$ or medium $\mathrm{N}$ (Table $3)$. Negative correlations were found between transmitted red light and readings using the SPAD-502 chlorophyll meter $\left(P<0.0001, r^{2}=0.53\right)$ and the MC-100 chlorophyll meter $\left(P<0.0001, r^{2}=0.44\right)$ (Fig. 4). On the other hand, $\mathrm{N}$ treatment had no effect on NIR light intensity transmitted

Table 1. Relative chlorophyll content measured with a SPAD-502 chlorophyll meter (Konica Minolta, Tokyo, Japan), MC100 chlorophyll meter (Apogee Instruments, Logan, UT), and normalized difference vegetation index (NDVI) sensors (Apogee Instruments) under halogen lights or solar radiation. Buffaloberry plants were treated with nitrogen (N)-free Utah Monocot/Dicot solution (Bugbee, 2004) with $0 \mathrm{~mm}$ (zero N), $2 \mathrm{~mm}$ (medium N), or $4 \mathrm{~mm}$ (ample N) added ammonium nitrate $\left(\mathrm{NH}_{4} \mathrm{NO}_{3}\right)$. The relative chlorophyll content estimated using NDVI sensors $\left(\mathrm{Chl}_{\mathrm{NDVI}}\right)$ is the natural logarithm of the ratio of transmitted red light $(\mathrm{RED})$ and near-IR $(\mathrm{RED})\left[\mathrm{Ch} \mathrm{NDVI}_{\mathrm{N}}=\ln\right.$ (percent transmission of NIR/percent transmission of RED)].

\begin{tabular}{|c|c|c|c|c|c|}
\hline \multirow[b]{2}{*}{ Light condition } & \multirow[b]{2}{*}{ Instrument } & \multirow[b]{2}{*}{ Output } & \multicolumn{3}{|c|}{ Relative chlorophyll content } \\
\hline & & & Ample N & Medium N & Zero N \\
\hline \multirow[t]{3}{*}{ Halogen lights } & SPAD-502 meter & SPAD reading & $57.61 \mathrm{a}^{\mathrm{z}}$ & $56.00 \mathrm{a}$ & $33.95 \mathrm{~b}$ \\
\hline & MC-100 meter & chlorophyll content index & $56.51 \mathrm{a}$ & $60.83 a$ & $22.78 \mathrm{~b}$ \\
\hline & NDVI sensors & $\mathrm{Chl}_{\mathrm{NDVI}}$ & $2.11 \mathrm{a}$ & $2.24 \mathrm{a}$ & $1.68 \mathrm{~b}$ \\
\hline \multirow[t]{3}{*}{ Solar radiation } & SPAD-502 meter & SPAD reading & $52.29 \mathrm{a}$ & $56.23 \mathrm{a}$ & $30.74 \mathrm{~b}$ \\
\hline & MC-100 meter & chlorophyll content index & $43.87 \mathrm{a}$ & $57.18 \mathrm{a}$ & $16.66 \mathrm{~b}$ \\
\hline & NDVI sensors & $\mathrm{Chl}_{\mathrm{NDVI}}$ & $2.82 \mathrm{a}$ & $2.81 \mathrm{a}$ & $1.56 \mathrm{~b}$ \\
\hline
\end{tabular}

${ }^{\mathrm{z}}$ Means within each row with the same letters are similar at $P>0.05$ using the Tukey-Kramer method. 
Table 2. Absolute leaf chlorophyll a and b contents of buffaloberry treated with nitrogen (N)-free Utah Monocot/Dicot solution (Bugbee, 2004) with $0 \mathrm{~mm}$ $($ zero $\mathrm{N}$ ), $2 \mathrm{~mm}$ (medium $\mathrm{N})$, or $4 \mathrm{~mm}$ (ample $\mathrm{N}$ ) added ammonium nitrate $\left(\mathrm{NH}_{4} \mathrm{NO}_{3}\right)$. Three leaves were sampled from the top $(1 / 3$ main shoot $)$ or bottom ( $1 / 3$ main shoot) of each main shoot for determining leaf chlorophyll content. The chlorophyll contents sampled from the top and bottom of main shoot were averaged.

\begin{tabular}{|c|c|c|c|c|c|c|c|}
\hline & \multicolumn{6}{|c|}{ Chlorophyll concn $\left(\mathrm{g} \cdot \mathrm{m}^{-2}\right)^{\mathrm{z}}$} \\
\hline & & \multicolumn{2}{|c|}{ Ample N } & \multicolumn{2}{|c|}{ Medium N } & \multicolumn{2}{|c|}{ Zero $\mathbf{N}$} \\
\hline & & Top & Bottom & Top & Bottom & Top & Bottom \\
\hline \multirow[t]{2}{*}{ Leaf } & Chlorophyll a & $0.23 \mathrm{ab}^{\mathrm{y}}$ & $0.29 \mathrm{a}$ & $0.25 \mathrm{ab}$ & $0.24 \mathrm{ab}$ & $0.18 \mathrm{~b}$ & $0.07 \mathrm{c}$ \\
\hline & Chlorophyll b & $0.10 \mathrm{a}$ & $0.10 \mathrm{a}$ & $0.09 \mathrm{a}$ & $0.09 \mathrm{a}$ & $0.08 \mathrm{a}$ & $0.04 \mathrm{~b}$ \\
\hline \multirow[t]{2}{*}{ Avg } & Chlorophyll a & \multicolumn{2}{|c|}{$0.26 \mathrm{a}$} & \multicolumn{2}{|c|}{$0.25 \mathrm{a}$} & \multicolumn{2}{|c|}{$0.13 \mathrm{~b}$} \\
\hline & Chlorophyll b & \multicolumn{2}{|c|}{$0.1 \mathrm{a}$} & \multicolumn{2}{|c|}{$0.1 \mathrm{a}$} & \multicolumn{2}{|c|}{$0.06 \mathrm{~b}$} \\
\hline
\end{tabular}

${ }^{\mathrm{z}} 1 \mathrm{~g} \cdot \mathrm{m}^{-2}=0.0033 \mathrm{oz} / \mathrm{ft}^{2}$.

${ }^{\mathrm{y}}$ Means within each row with the same letters are similar at $P>0.05$ using the Tukey-Kramer method.

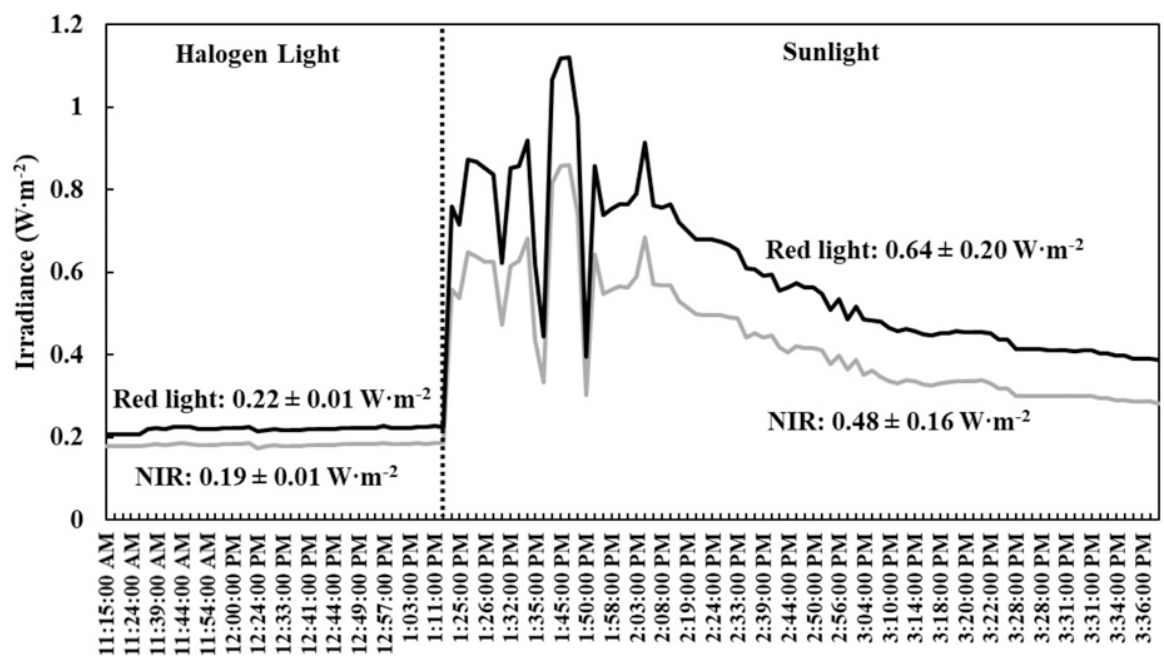

Fig. 3. Incident red light and near-infrared light (NIR) of halogen lights and sunlight with their mean and SD. Two 500-W halogen lights (PQS45; Regent Lighting, Basel, Switzerland) in a darkroom at the Utah State University (USU) research greenhouse were measured using an upward-looking normalized difference vegetation index sensor (S2-411-SS; Apogee Instruments, Logan, UT) that was placed $84 \mathrm{~cm}$ (33.1 inches) from the lights. Incident red and NIR of sunlight were recorded from 1321 to $1536 \mathrm{HR}$ on 16 Nov. 2019 in an open field of the USU research greenhouse (lat. $41^{\circ} 45^{\prime} 28^{\prime \prime} \mathrm{N}$, long. $111^{\circ} 48^{\prime} 47^{\prime \prime} \mathrm{W}$ ). $1 \mathrm{~W} \cdot \mathrm{m}^{-2}=0.0929 \mathrm{~W} / \mathrm{ft}^{2}$.

through leaves (Table 3 ). No correlation was found between transmitted NIR light and readings using the SPAD502 chlorophyll meter or the MC-100 chlorophyll meter when using halogen lights (Fig. 5). Chl $\mathrm{NDVI}_{\text {of }}$ plants treated with ample $\mathrm{N}$ or medium $\mathrm{N}$ was greater than that treated with zero N (Table 1 ). There were positive correlations between $\mathrm{Chl}_{\text {NDVI }}$ and readings of the SPAD-502 chlorophyll meter $(P<$ $\left.0.0001, r^{2}=0.65\right)$ and the MC-100 chlorophyll meter $\left(P<0.0001, r^{2}=\right.$ 0.56) (Fig. 6). readings $[P=0.04$ (Fig. 5) $]$, but not with CCI. In addition, $\mathrm{Ch}_{\mathrm{NDVI}}$ in the ample $\mathrm{N}$ and medium $\mathrm{N}$ treatments was greater than that in the zero $\mathrm{N}$ treatment (Table 1). Moreover, $\mathrm{Chl}_{\text {NDVI }}$ values correlated positively with readings from the SPAD-502 chlorophyll meter $\left(P<0.0001, r^{2}=\right.$ 0.82 ) and the MC-100 chlorophyll meter $\left(P<0.0001, r^{2}=0.70\right)($ Fig. 6)

\section{Discussion}

Measurements of chlorophyll content with NDVI sensors can be made under sunlight or electric lamps that emit red and NIR light. The challenge of estimating chlorophyll levels by the transmitted red and NIR light from sunlight is the sensitivity of red and NIR light detectors to changes in ambient red and NIR light. Although halogen lights contain a large amount of NIR light, the NIR light level of halogen lights was still $60 \%$ less than that in sunlight in our study (Fig. 3). Fortunately, the NDVI sensor used in our study was sensitive to low signals and could detect the transmitted red and NIR light accurately. Leaves from plants receiving ample $\mathrm{N}$ and medium $\mathrm{N}$, which had no chlorosis and greater chlorophyll content, showed lower percent transmission of red light. Although most optical chlorophyll meters estimate chlorophyll content using dual-wavelength red and NIR light detectors, single-wavelength sensors have also been developed to estimate chlorophyll content by transmitted red light (Monje and Bugbee, 1992).

Leaves of buffaloberry treated with zero $\mathrm{N}$ had a lower transmitted NIR light than those with ample $\mathrm{N}$ (Table 3). This indicates that leaves from plants with zero $\mathrm{N}$ absorbed or reflected more NIR light than the plants fertilized with N. Leaves of buffaloberry are covered with trichomes (Sriladda et al., 2016), and the trichome density might increase at a lower $\mathrm{N}$ treatment, leading to greater absorbance and reflectance of NIR light. In addition to chlorophyll, other plant pigments and structures can affect red absorption and thus interfere with measurements of chlorophyll indices that are solely based on transmitted red light. Therefore, transmitted NIR light is used as a reference wavelength in dual-wavelength measurements to correct the effects of nonchlorophyll absorbance (Monje and 
Table 3. Transmitted red and near-infrared (NIR) light (percent) measured with normalized difference vegetation index sensors (Apogee Instruments, Logan, UT) under halogen lights or solar radiation. Buffaloberry plants were treated with nitrogen (N)-free Utah Monocot/Dicot solution (Bugbee, 2004) with $0 \mathrm{~mm}$ (zero $\mathrm{N}), 2 \mathrm{~mm}($ medium $\mathrm{N})$, or $4 \mathrm{~mm}(\operatorname{ample} \mathrm{N})$ added ammonium nitrate $\left(\mathrm{NH}_{4} \mathrm{NO}_{3}\right)$.

\begin{tabular}{lcccr}
\hline & & \multicolumn{3}{c}{ Transmitted light (\%) } \\
\cline { 3 - 5 } Light condition & Output & Ample N & Medium N & Zero N \\
\hline Halogen lights & Red & $1.23 \mathrm{~b}^{\mathrm{z}}$ & $1.26 \mathrm{~b}$ & $2.03 \mathrm{a}$ \\
& NIR & $10.21 \mathrm{a}$ & $11.49 \mathrm{a}$ & $10.06 \mathrm{a}$ \\
Solar radiation & Red & $0.83 \mathrm{~b}$ & $0.80 \mathrm{~b}$ & $2.73 \mathrm{a}$ \\
& NIR & $13.65 \mathrm{a}$ & $12.21 \mathrm{ab}$ & $10.43 \mathrm{~b}$ \\
\hline
\end{tabular}

${ }^{\mathrm{z}}$ Means within each row with the same letters are similar at $P>0.05$ using the Tukey-Kramer method.
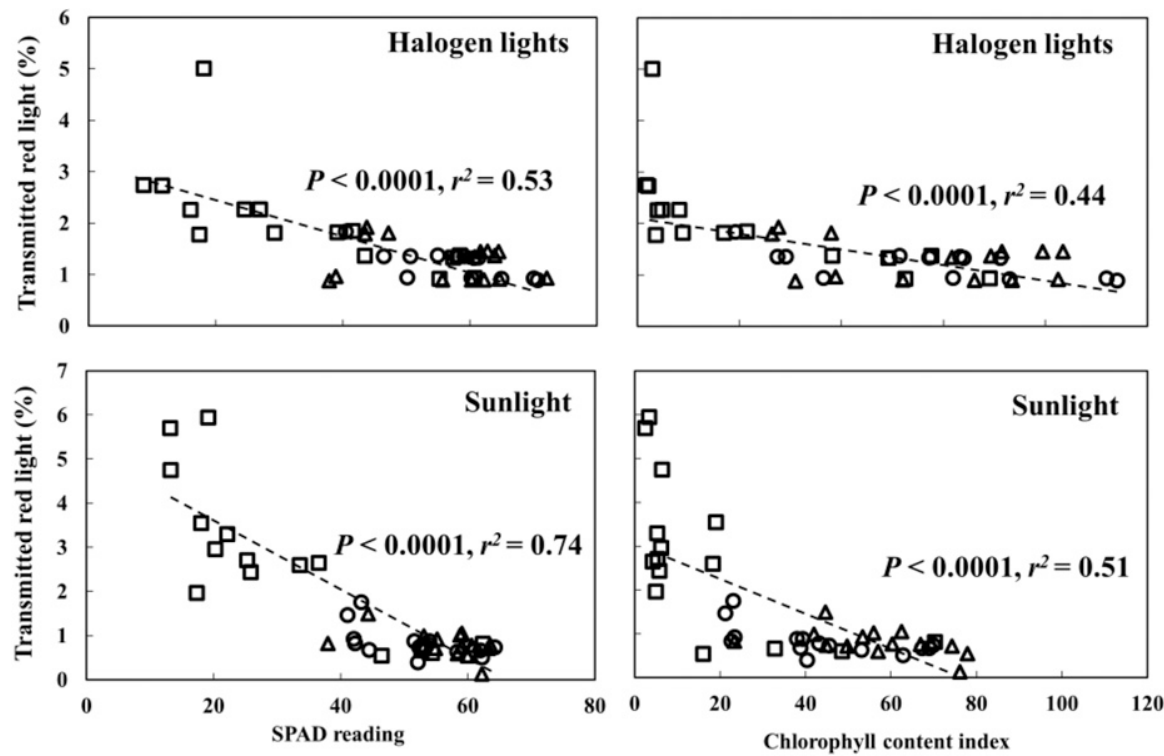

Fig. 4. Correlation between transmitted red light (percent) measured using normalized difference vegetation index sensors (Apogee Instruments, Logan, UT) and readings from a SPAD-502 chlorophyll meter (Konica Minolta, Tokyo, Japan) (SPAD reading) or the chlorophyll content index from an MC-100 chlorophyll meter (Apogee Instruments) under halogen light or sunlight. Measurements were recorded on leaves from buffaloberry plants treated with nitrogen $(\mathrm{N})$-free Utah Monocot/Dicot solution (Bugbee, 2004) with $0 \mathrm{~mm}$ (zero N), $2 \mathrm{~mm}$ (medium N), or $4 \mathrm{~mm}$ (ample $\mathrm{N}$ ) added ammonium nitrate for 3 weeks.

Bugbee, 1992). In our study, a significant positive correlation was found between $\mathrm{Chl}_{\mathrm{NDVI}}$ and readings of optical chlorophyll meters under either solar radiation or halogen lights (Fig. 6 ), which indicates that the $\mathrm{Ch}_{\mathrm{NDVI}}$ measured with NDVI sensors can provide a reliable estimate of leaf chlorophyll content under sunlight and electric light that contain red and NIR light. The correlation between $\mathrm{Chl}_{\mathrm{NDVI}}$, and SPAD and CCI was stronger under sunlight (all $r^{2}>$ $0.70)$ than under halogen lights $\left(r^{2}=\right.$ 0.65 and 0.56 ). This might be associated with the fact that sunlight during our measurement had greater levels of red and NIR radiation. Nevertheless, compared with the optical chlorophyll content meters containing built-in LEDs that provide constant red and NIR radiation, a limitation of using NDVI sensors to evaluate chlorophyll content might be that the sensitivity is proportional to incident red and NIR light intensities. Under most circumstances, sunlight is easily accessible and provides high amounts of red and NIR light for reliable measurements.

Another concern when using chlorophyll meters to estimate leaf chlorophyll content is the measurement area. Larger measurement areas provide a larger spatial average, but it is difficult to make measurements on plants with narrow leaf blades (Parry et al., 2014). For instance, chlorophyll content measurements are difficult to make using a chlorophyll meter on turfgrasses with narrow leaves (Rodriguez and Miller, 2000). Thus, requiring a larger measurement area restricts measurements to species with relatively broad leaves. The measurement area of an MC-100 chlorophyll meter is $63 \mathrm{~mm}^{2}$, and the SPAD-502 is $6 \mathrm{~mm}^{2}$. The narrow field of view of the NDVI sensors allows them to make reliable measurements in species with small leaf areas.

Measurements using the SPAD$502, \mathrm{MC}-100$, and the NDVI sensor on the same leaf were comparable because chlorophyll distribution was uniform in the leaves of buffaloberry. Nonuniformity of chlorophyll in leaves may lead to variations in chlorophyll content measurements as transmission decreases at higher chlorophyll concentrations but increases at lower chlorophyll concentrations (Parry et al., 2014). Therefore, uniform leaf chlorophyll distribution is important for comparing different methods of chlorophyll measurements (Monje and Bugbee, 1992). For buffaloberry, the CV of chlorophyll distribution was $11 \%$. Therefore, with uniform chlorophyll distribution, the measurements recorded on the same leaves with different meters and the NDVI sensor were comparable. As a result of significant positive correlations found between measurements using the NDVI sensor and the chlorophyll meters, NDVI sensors can be used to estimate relative chlorophyll content. In addition, NDVI sensors (or a specialized chlorophyll content sensor developed using a similar technique) can be connected to automated data-logging devices and thus could potentially be used to monitor leaf chlorophyll status continuously.

Sensors with red light/far-red light detection are becoming widely used (Kusuma and Bugbee, 2021). With the addition of a micro data $\log$ ger (microCache, Apogee Instruments) featuring wireless connection to mobile devices, these sensors are easier to use. Because our research proved the concept that chlorophyll content can be estimated using an NDVI sensor, researchers can create a sensor with red and NIR light detection, allowing growers to estimate 

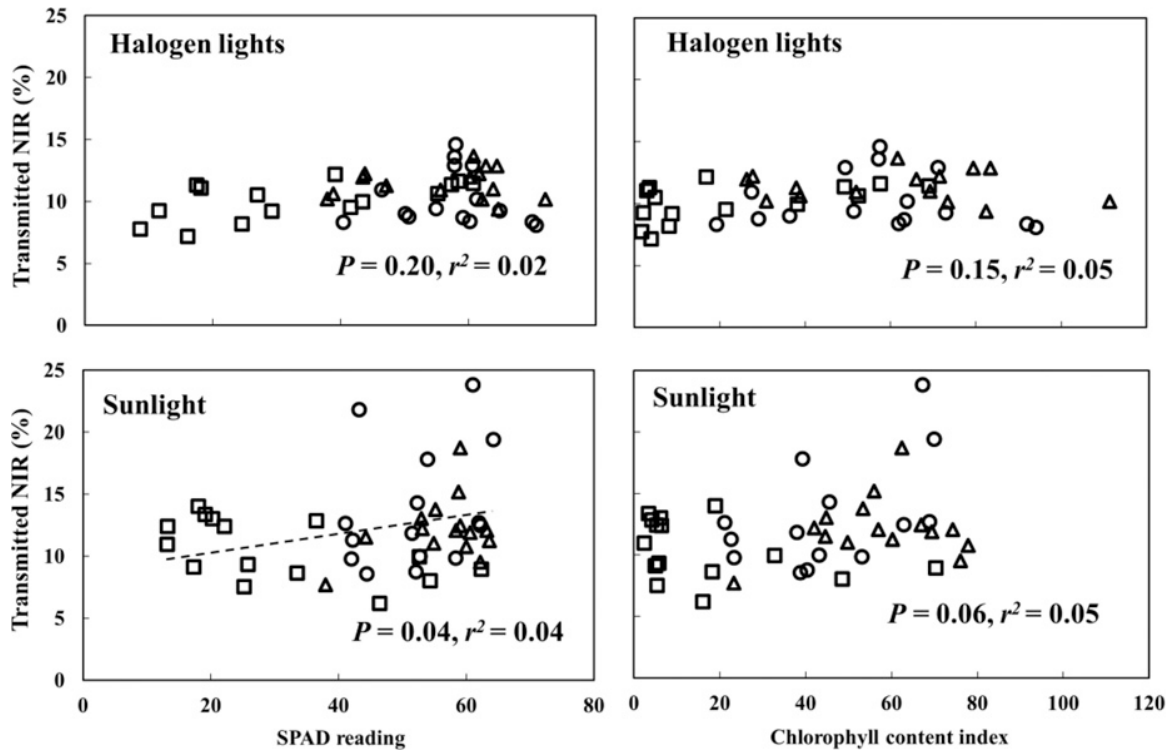

Fig. 5. Correlation between transmitted near-infrared light (NIR) (percent) measured using normalized difference vegetation index sensors (Apogee Instruments, Logan, UT) and readings from a SPAD-502 chlorophyll meter (Konica Minolta, Tokyo, Japan) (SPAD reading) or the chlorophyll content index from an MC-100 chlorophyll meter (Apogee Instruments) under halogen light or sunlight. Measurements were recorded on leaves from buffaloberry plants treated with nitrogen (N)-free Utah Monocot/Dicot solution (Bugbee, 2004) with $0 \mathrm{~mm}$ (zero $\mathrm{N}), 2 \mathrm{~mm}($ medium $\mathrm{N})$, or $4 \mathrm{~mm}($ ample $\mathrm{N}$ ) added ammonium nitrate for 3 weeks.
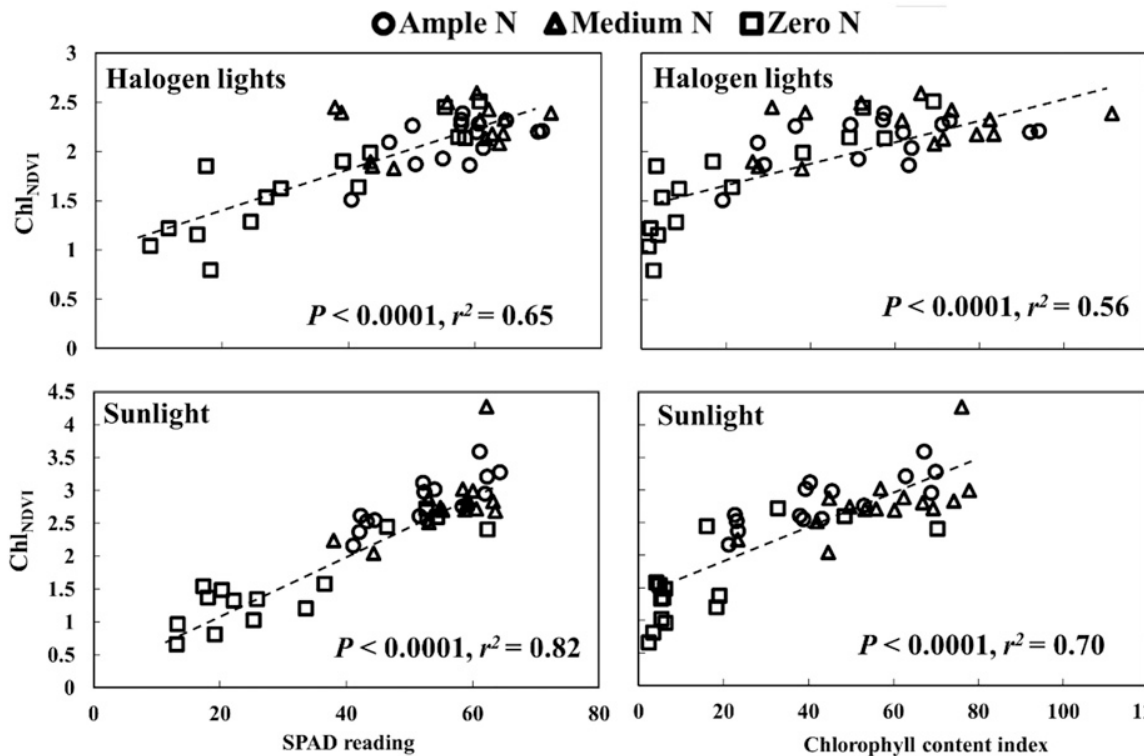

Fig. 6. Correlation between relative chlorophyll content estimated with normalized difference vegetation index ( $\left.\mathrm{Chl}_{\mathrm{NDVI}}\right)$ sensors (Apogee Instruments, Logan, UT)] and readings from a SPAD-502 chlorophyll meter (Konica Minolta, Tokyo, Japan) (SPAD reading) or the chlorophyll content index from an MC-100 chlorophyll meter (Apogee Instruments) under halogen light or sunlight. Measurements were recorded on leaves from buffaloberry plants treated with nitrogen (N)-free Utah Monocot/Dicot solution (Bugbee, 2004) with $0 \mathrm{~mm}$ (zero $\mathrm{N}), 2 \mathrm{~mm}$ (medium $\mathrm{N}$ ), or $4 \mathrm{~mm}$ (ample $\mathrm{N}$ ) added ammonium nitrate for 3 weeks. chlorophyll content to improve plant growth and nutrient status in greenhouse production.

\section{Conclusion}

Sensors with dual detectors, such as NDVI sensors, are widely used in remote-sensing and controlled environmental studies. Our research showed that transmitted red light or $\mathrm{Chl}_{\mathrm{NDVI}}$ (calculated based on the ratio of transmitted NIR and red light) recorded by the NDVI sensor could be used to detect the difference in leaf chlorophyll contents of buffaloberry under halogen light and sunlight with consistent results compared with SPAD and CCI measurements. Therefore, a sensor with dual detectors (red and NIR light) can provide a reliable, nondestructive method for evaluating relative chlorophyll content. Also, the NDVI sensor used in this study has a narrow measurement area that is helpful for recording data on plants with small leaves. Moreover, sunlight can be used as a reliable and easily accessible light source. Our research proved the concept that a sensor that is similar to the red/far-red light sensor with red and NIR light detection could be developed to help growers estimate chlorophyll content and adjust fertilizer applications to improve plant growth and nutrient status.

\section{Literature cited}

Bugbee, B. 2004. Nutrient management in recirculating hydroponic culture. Acta Hort. 648:99-112, doi: 10.17660/ActaHortic.2004.648.12.

Chen, J., H. Kratsch, J. Norton, Y. Sun, and L. Rupp. 2020. Nodulation and plant growth of Shepherdia $\times$ utahensis 'Torrey' topdressed with controlled-release fertilizer. HortScience 55:1956-1962, doi: 10.21273/HORTSCI15260-20.

Ferrarezi, R., T.C. Geiger, J. Greenidge, S. Dennery, S.A. Weiss, and G.S. Vieira. 2020. Microirrigation equipment for okra cultivation in the U.S. Virgin Islands. HortScience 55:1045-1052, doi: 10.21273/HORTSCI15021-20.

Kalaji, H.M., P. Dąbrowski, M.D. Cetner, I.A. Samborska, I. Łukasik, M. Brestic, M. Zivcak, H. Tomasz, J. Mojski, H. Kociel, and B.M. Panchal. 2017. A comparison between different chlorophyll content meters under nutrient deficiency conditions. J. Plant Nutr. 40:1024-1034, doi: 10.1080/01904167.2016.1263323.

Kusuma, P. and B. Bugbee. 2021. Farred fraction: An improved metric for 
characterizing phytochrome effects on morphology. J. Amer. Soc. Hort. Sci. 146: 3-13, doi: 10.21273/JASHS05002-20.

Monje, O.A. and B. Bugbee. 1992. Inherent limitations of nondestructive chlorophyll meters: A comparison of two types of meters. HortScience 27:69-71, doi: 10.21273/HORTSCI.27.1.69.

Neilsen, D., E.J. Hogue, G.H. Neilsen, and P. Parchomchuk. 1995. Using SPAD502 values to assess the nitrogen status of apple trees. HortScience 30:508-512, doi: 10.21273/HORTSCI.30.3.508.

Parry, C., J.M. Blonquist, and B. Bugbee. 2014. In situ measurement of leaf chlorophyll concentration: Analysis of the optical/ absolute relationship. Plant Cell Environ. 37:2508-2520, doi: 10.1111/pce.12324.

Richardson, A.D., S.P. Duigan, and G.P. Berlyn. 2002. An evaluation of noninvasive methods to estimate foliar chlorophyll content. New Phytol. 153:185-
194, doi: 10.1046/j.0028-646X.2001. 00289.x.

Rodriguez, I.R. and G.L. Miller. 2000. Using a chlorophyll meter to determine the chlorophyll concentration, nitrogen concentration, and visual quality of St. Augustinegrass. HortScience 35:751-754, doi: 10.21273/HORTSCI.35.4.751.

Sriladda, C., H.A. Kratsch, S.R. Larson, T.A. Monaco, F. Shen, and R.K. Kjelgren. 2016. Interspecific hybrid of xeric Shepherdia rotundifolia and riparian Shepherdia argentea: Description, and traits suitable for low-water urban landscapes. HortScience 51:822-828, doi: 10.21273/HORTSCI.51.7.822.

Taiz, L., E. Zeiger, I.M. Møller, and A. Murphy. 2015. Plant physiology and development. 6th ed. Sinauer Associates, Sunderland, MA.

Vesali, F., M. Omid, A. Kaleita, and H. Mobi. 2015. Development of an android app to estimate chlorophyll content of corn leaves based on contact imaging. Comput. Electron. Agr. 116: 211-220, doi: $10.1016 / j . c o m p a g$. 2015.06.012.

Wang, Y., B.L. Dunn, D.B. Arnall, and P. Mao. 2012. Use of an active canopy sensor and SPAD chlorophyll meter to quantify geranium nitrogen status. HortScience 47:45-50, doi: 10.21273/ HORTSCI.47.1.45.

Wellburn, A.R. 1994. The spectral determination of chlorophyll-a and chlorophyll-b, as well as total carotenoids, using various solvents with spectrophotometers of different resolution. J. Plant Physiol. 144:307-313, doi: 10.1016/S0176-1617(11)81192-2.

Yang, W., S. Peng, J. Huang, A.L. Sanico, R.J. Buresh, and C. Witt. 2003. Using leaf color charts to estimate leaf nitrogen status of rice. Agron. J. 95:212-217. 